\title{
Efficacy of a novel bipolar radiofrequency ablation device on the beating heart for atrial fibrillation ablation: A long-term porcine study
}

\author{
Rochus K. Voeller, MD, Andreas Zierer, MD, Shelly C. Lall, MD, Shun-ichiro Sakamoto, MD, \\ Richard B. Schuessler, PhD, and Ralph J. Damiano, Jr, MD
}

\begin{abstract}
Objective: Over recent years, a variety of energy sources have been used to replace the traditional incisions of the Cox maze procedure for the surgical treatment of atrial fibrillation. This study evaluated the safety and efficacy of a new bipolar radiofrequency ablation device for atrial ablation in a long-term porcine model.
\end{abstract}

\begin{abstract}
Methods: Six pigs underwent a Cox maze IV procedure on a beating heart off cardiopulmonary bypass using the AtriCure Isolator II bipolar ablation device (AtriCure, Inc, Cincinnati, Ohio). In addition, 6 pigs underwent median sternotomy and pericardiotomy alone to serve as a control group. All animals were allowed to survive for 30 days. Each pig underwent induction of atrial fibrillation and was then humanely killed to remove the heart en bloc for histologic assessment. Magnetic resonance imaging scans were also obtained preoperatively and postoperatively to assess atrial and ventricular function, pulmonary vein anatomy, valve function, and coronary artery patency.
\end{abstract}

\begin{abstract}
Results: All animals survived the operation. Electrical isolation of the left atrial appendage and the pulmonary veins was documented by pacing acutely and at 30 days in all animals. No animal that underwent the Cox maze IV procedure was able to be induced into atrial fibrillation at 30 days postoperatively, compared with all the sham animals. All 257 ablations examined were discrete, linear, and transmural, with a mean lesion width of $2.2 \pm 1.1 \mathrm{~mm}$ and a mean lesion depth of $5.3 \pm 3.0 \mathrm{~mm}$.
\end{abstract}

Conclusions: The AtriCure Isolator II device was able to create reliable long-term transmural lesions of the modified Cox maze procedure on a beating heart without cardiopulmonary bypass $100 \%$ of the time. There were no discernible effects on ventricular or valvular function. (J Thorac Cardiovasc Surg 2010;140:203-8)

In an attempt to treat patients in whom medical treatment for atrial fibrillation (AF) failed, the Cox maze procedure was developed two decades ago at our institution. ${ }^{1-3}$ Introduced clinically in 1987, the Cox maze III procedure became the gold standard for the surgical treatment of AF. Although this "cut-and-sew" procedure had excellent results with long-term cure rates of over $90 \%$, it was not widely adopted by most cardiac surgeons owing to its associated morbidity, technical complexity, and invasiveness. ${ }^{4-9}$

The introduction of surgical ablation technology over the past decade has advanced the field of AF surgery tremendously. ${ }^{10-12}$ Centers around the world have replaced the sur-

\footnotetext{
From the Division of Cardiothoracic Surgery, Washington University School of Medicine, Barnes-Jewish Hospital, St Louis, Mo.

Supported by the National Institutes of Health Grants R01 HL032257-21 and F32 HL082129-02.

Disclosures: The study was supported by AtriCure; Ralph Damiano reports advisory and lecture fees from AtriCure; Richard Schuessler reports advisory and lecture fees and grant support from AtriCure.

Received for publication May 12, 2009; revisions received May 16, 2009; accepted for publication June 8, 2009; available ahead of print Feb 1, 2010.

Address for reprints: Ralph J. Damiano, Jr, MD, Washington University School of Medicine, Barnes-Jewish Hospital, Suite 3108 Queeny Tower, 1 Barnes-Jewish Hospital Plaza, St Louis, MO 63110 (E-mail: damianor@wustl.edu). $0022-5223 / \$ 36.00$

Copyright $(C) 2010$ by The American Association for Thoracic Surgery doi:10.1016/j.jtcvs.2009.06.034
}

gical incisions of the Cox maze III with ablation lines on the atria using a variety of energy sources, simplifying the operation and making it more accessible to surgeons worldwide.

After extensive investigation, our laboratory has shown that bipolar radiofrequency $(\mathrm{RF})$ ablation can safely create reliable transmural lesions and be successfully used to replace most of the surgical incisions of the original "cutand-sew" Cox maze III procedure. ${ }^{13-16}$ At Washington University School of Medicine, the bipolar RF ablationassisted Cox maze procedure, termed the Cox maze IV, has clinically replaced the Cox maze III procedure. ${ }^{17}$ Early and midterm clinical experience with the Cox maze IV procedure have shown excellent results, with significantly shorter cardiopulmonary bypass and crossclamp times. ${ }^{18-22}$ A recent propensity analysis performed by our group on matched patients who underwent the Cox maze III versus Cox maze IV procedure found no difference in freedom from AF recurrence at 1 year. $^{23}$

The purpose of this study was to evaluate the performance of a new generation bipolar RF ablation device, the Isolator II system, developed by AtriCure, Inc (Cincinnati, Ohio). In a long-term porcine model, a Cox maze IV procedure was performed. ${ }^{15,16}$ The Isolator II device was developed in an attempt to create wider lesions that can be more easily visualized by the surgeon intraoperatively and also to reliably 


$$
\begin{aligned}
& \text { Abbreviations and Acronyms } \\
& \mathrm{AF}=\text { atrial fibrillation } \\
& \mathrm{EF}=\text { ejection fraction } \\
& \mathrm{IVC}=\text { inferior vena cava } \\
& \mathrm{LAA}=\text { left atrial appendage } \\
& \mathrm{MRI}=\text { magnetic resonance imaging } \\
& \mathrm{PV}=\text { pulmonary vein } \\
& \mathrm{RF}=\text { radiofrequency } \\
& \mathrm{SVC}=\text { superior vena cava }
\end{aligned}
$$

penetrate thicker atrial tissue. Several changes in the algorithm of the ablation system and in the mechanical properties of the device were made in an attempt to make these improvements. A sham group $(n=6)$ of animals was also examined to determine the effects of a median sternotomy and pericardotomy alone.

\section{METHODS}

\section{Experimental Protocol}

Twelve domestic pigs weighing 60 to $75 \mathrm{~kg}$ were used in this study. All animals received humane care in compliance with the "Guide for the Care and Use of Laboratory Animals," published by the National Institutes of Health (National Institutes of Health publication 85-23, revised 1985). The study was also approved by the Washington University School of Medicine Animal Studies Committee.

Six pigs in the study group underwent preoperative cardiac magnetic resonance imaging (MRI) under anesthesia to assess left ventricular and left atrial ejection fractions (EFs), tricuspid and mitral valve function, pulmonary vein (PV) anatomy and flow, and coronary artery anatomy and flow. A Cox maze IV procedure was subsequently performed on the beating heart without cardiopulmonary bypass. The animal was premedicated, intubated, and anesthetized with $2 \%$ to $4 \%$ isoflurane and was placed on continuous hemodynamic monitoring throughout the procedure. A median sternotomy was performed, and the heart was exposed via a pericardiotomy after administration of amiodarone (150 $\mathrm{mg}$ intravenous bolus every hour) to prevent arrhythmias. The heart was positioned using a suction retractor (AXIUS Xpose 3; Guidant Corp, Santa Clara, Calif). Baseline pacing thresholds were obtained from the right and left PVs and at the left atrial appendage (LAA) using a bipolar pacing device.

The left and right PVs, superior vena cava (SVC), and inferior vena cava (IVC) were bluntly dissected and isolated using umbilical tapes. The pigs were fully heparinized ( 350 units $/ \mathrm{kg}$, intravenously), and the activated clotting time was maintained greater than 250 seconds. The Cox maze IV ablation set was performed off cardiopulmonary bypass as previously described (Figure 1). ${ }^{15}$ In brief, the right and left PVs were isolated individually, and a connecting lesion was performed between the right and left PVs. The right atrial lesion set was then performed via a single atriotomy at the tip of the right atrial appendage, followed by the SVC and IVC lesions through a purse-string suture placed midway between the confluence of the SVC and IVC. The left atrial lesion set was created via an atriotomy on the anterior surface of the LAA. Last, the LAA itself was circumferentially ablated.

The only variation in the Cox maze IV ablation set from our previous studies was the omission of the right atrial appendage ablation to more closely mimic the clinical procedure (Figure 1). The ablation lines were purposefully created across the mitral and tricuspid valves and across the right coronary and circumflex coronary arteries to assess ablation safety. All ablations were performed a single time only. After completion of the abla-

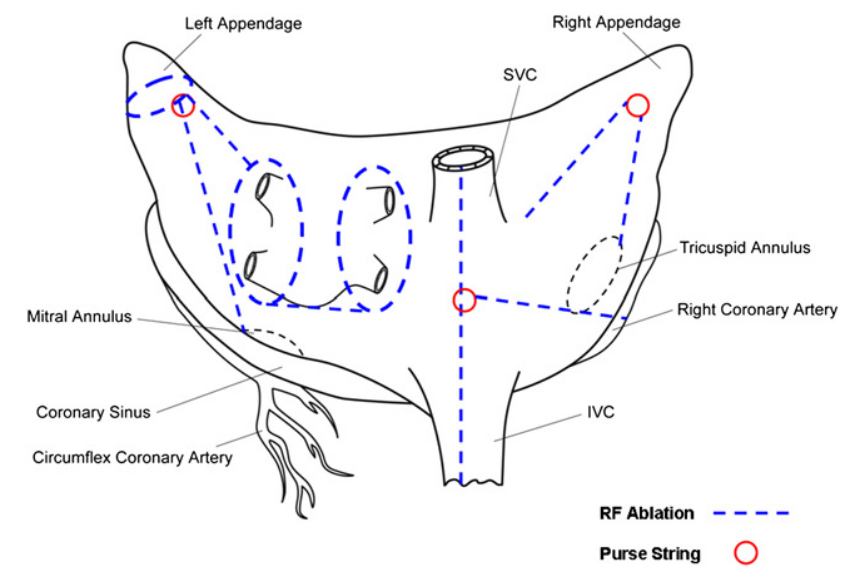

FIGURE 1. The modified Cox maze procedure lesion set. All lesions were created off cardiopulmonary bypass using the Atricure Isolator II bipolar radiofrequency ablation device. $S V C$, Superior vena cava; $I V C$, inferior vena cava; $R F$, radiofrequency.

tions, electrical isolation was confirmed by pacing distal to the ablation lines at the right and left PVs and at the LAA. Pacing was performed at the sites previously documented to capture before ablation. Pacing was performed up to the maximal output of our stimulator $(20 \mathrm{~mA})$ to document exit block. The pericardium was then closed and the sternum was reapproximated. A chest tube was placed before sternal closure and was removed during recovery. The entire procedure was completed in approximately 2 hours.

In addition to the study group, 6 pigs underwent median sternotomy and pericardiotomy alone to serve as the sham group. All animals in both groups were closely monitored for 48 hours and were allowed to survive for 30 days. Daily aspirin $81 \mathrm{mg}$ by mouth was given, beginning on the first day after the operation. No antiarrhythmic drugs were administered.

At 30 days postoperatively, the study group underwent a follow-up cardiac MRI to reassess the cardiac measurements. All animals in both groups underwent redo median sternotomy. Meticulous adhesiolysis was performed to expose the entire heart and the PVs. Chronic electrical isolation was confirmed by failure to capture by epicardial pacing $(20 \mathrm{~mA}$, 5-ms pulse duration) of the right and left PVs and at the LAA, distal to the ablation lines. Finally, AF induction was attempted by 2 trials of rapid pacing from the right atrial free wall for 30 seconds $(20 \mathrm{~mA}, 400 \mathrm{~ms}, 150$ beats/min). If unsuccessful, 2 trials of burst pacing were performed from the right atrial free wall with $8 \mathrm{~S} 1$ at a cycle length of $150 \mathrm{~ms}$ followed by a single extra stimulus $\mathrm{S} 2$ of $90 \mathrm{~ms}$. If still unsuccessful, a $2.5-\mathrm{mg}$ bolus of intravenous neostigmine was given, and the rapid pacing protocol was repeated, followed by burst pacing. At the conclusion of the study, the animal was humanely killed by administering potassium chloride, $80 \mathrm{mEq}$ intravenous bolus, and the heart was removed en bloc for histologic assessment.

\section{Bipolar RF Ablation Device}

The bipolar RF ablation system, the AtriCure Isolator II Ablation System, was used to create the modified Cox maze lesion set in this study (Figure 2). The ablation instrument consisted of 2 jaws in parallel with opposing electrodes, clamped on target tissue during ablation. Energy was delivered from the ablation and sensing unit to the instrument with an algorithm based on the assessment of tissue conductance every 10th of a second. This algorithm has been previously described. ${ }^{13,14}$

The Isolator II Ablation System was designed to create wider ablation lines that would be easier for the surgeon to visualize when compared with the original Isolator device. The electrode width remained the same at $3 \mathrm{~mm}$, but the electrode length on the jaws was slightly shorter with the Isolator II device $(5.3 \mathrm{~cm}$ vs $6.4 \mathrm{~cm})$. The mechanical properties of the clamp were changed to create more even pressure from the heel to the 

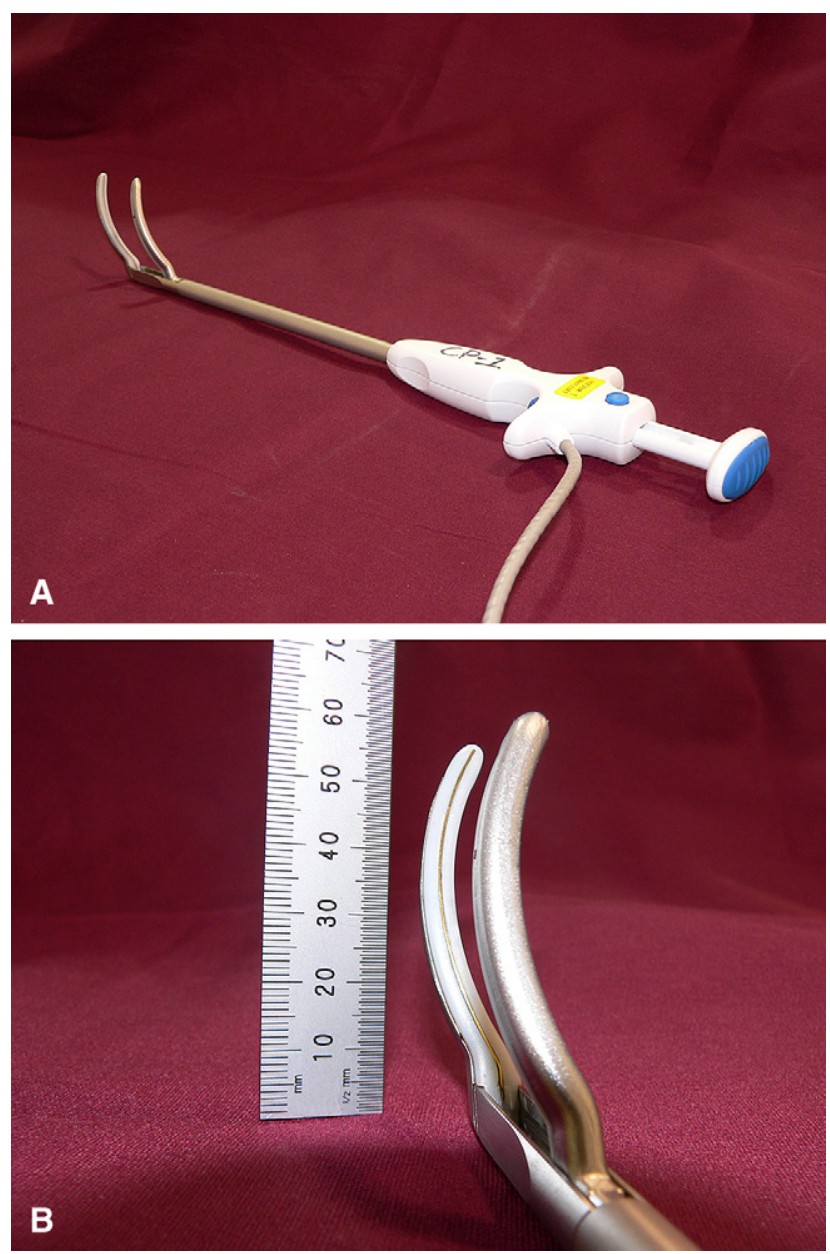

FIGURE 2. The Atricure Isolator II device. A, The clamp with a new handpiece. B, Close-up view of the jaw of the Atricure Isolator II device.

tip of the jaw. This was accomplished by redesigning the handle grip and shaft into a plunger mechanism for more direct application of pressure. The algorithm was also changed. The constant current limit (amps) and constant power limit (watts) for this range of tissue conductance was lowered to slow the ablation time, allowing for resistive heating to reach greater tissue depth and theoretically allowing for better depth penetration for ablation of thicker tissue. Although these changes were theoretically beneficial, this device has not been previously tested in an intact animal.

\section{Histologic and Microscopic Analysis}

The excised heart en bloc was grossly examined for any evidence of intra-atrial thrombus formation, PV stenosis, or thrombosis. The heart was then immediately incubated at room temperature for 45 minutes in $1 \%$ 2,3,5-triphenyl-tetrazolium chloride solution. Each bipolar RF lesion was then sectioned 5-mm apart, perpendicular to the long axis of the ablation line. The sections were fixed in formalin, molded in paraffin, and sectioned and stained with hematoxylin and eosin and Masson trichrome stains. Each section was examined under the microscope to assess the lesion width, depth, and transmurality. Data are expressed as mean \pm standard deviation.

\section{Cardiac MRI Protocol}

Each animal was anesthetized, intubated, placed in a supine position into a 1.5-T MRI scanner (Philips Medical Systems, Andover, Mass), and fitted with a 5-element dedicated cardiac surface coil for image reception. Multi- ple anatomic and functional cine images and velocity-encoded images were obtained using retrospectively gated breath-held balanced turbo field echo method with parallel imaging as previously described. ${ }^{15}$ High-resolution cine loops of the horizontal long-axis, short-axis, and left ventricular outflow tract views were obtained during a sequence of breath-holds. Approximately 20 short-axis stacks were generated, $8 \mathrm{~mm}$ apart with zero gap, spanning from the left ventricular apex through the left atrium.

\section{Cardiac MRI Data Analysis}

The acquired MRI data were analyzed off-line using a remote Sun Microsystems workstation running EasyVision analysis software (Philips Release 5.1). Left atrial and left ventricular volumes were assessed by planimetry as previously described. ${ }^{15}$ Left ventricular and left atrial EFs were defined as ([end-diastolic volume - end-systolic volume] divided by end-diastolic volume)

Transtricuspid and transmitral blood flows were assessed using velocityencoded MRI. ${ }^{24}$ MRI was also used to assess anatomic and physiologic flow patterns in the PV system. Finally, coronary artery anatomy and patency were assessed using the technique of Botnar and associates, ${ }^{25}$ which uses a navigator-gated free-breathing T2-weighted prepared turbo field echo acquisition.

\section{RESULTS \\ Operative Results}

All animals in both groups survived the operation and the 30-day postoperative period. There was no evidence of postoperative cardiac arrhythmias, and each animal was in sinus rhythm during the initial operation and at the time of being humanely killed. There were no signs of neurologic complications during the postoperative period.

\section{Acute and Chronic Pacing}

Acutely, electrical isolation of the LAA and right and left PVs was documented by pacing in all 6 animals in the study group. This was repeated at 30 days after the operation as well, which also revealed electrical isolation in every animal. Attempts to induce AF at 30 days were unsuccessful in all 6 animals. In the sham group, however, AF was inducible in all 6 animals after the protocol described.

\section{Histology}

There was no gross evidence of intra-atrial thrombus formation or stricture of the PVs. The triphenyl-tetrazolium chloride-stained ablation lines were carefully examined, all of which appeared linear, pale, discrete lesions over $2 \mathrm{~mm}$ in width.

Microscopic examination of the ablation lines with hematoxylin and eosin and Masson trichrome stains revealed discrete, linear, and pale lesions (Figure 3). A total of 257 samples were examined. Each lesion examined was transmural. The mean overall lesion width was $2.2 \pm 1.1 \mathrm{~mm}$, and the mean lesion depth was $5.3 \pm 3.0 \mathrm{~mm}$. The mean lesion width in this study was wider than in our previous studies using the original Isolator device, in which the mean lesion widths were less than $2 \mathrm{~mm} .{ }^{13-15,26}$ Compared with our recent study using the Isolator device, the mean ablation time was slightly longer $(9.9 \pm 4.6$ seconds vs $8.6 \pm 3.1$ 


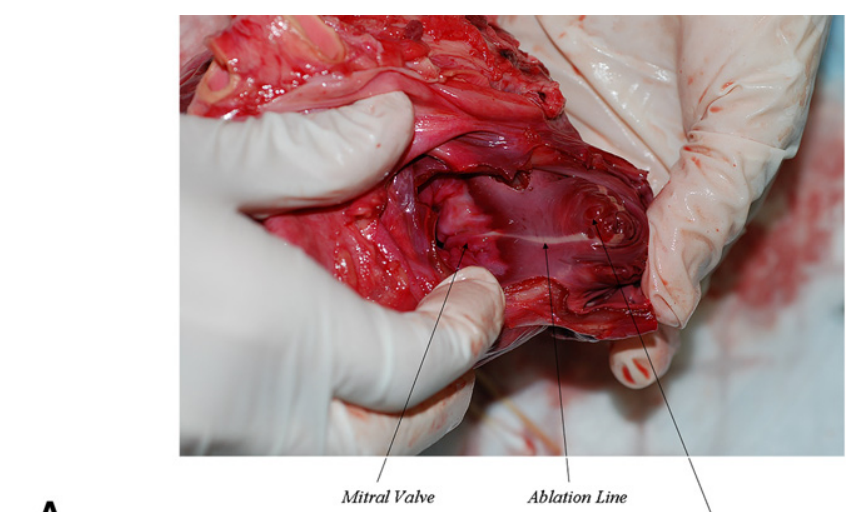

A

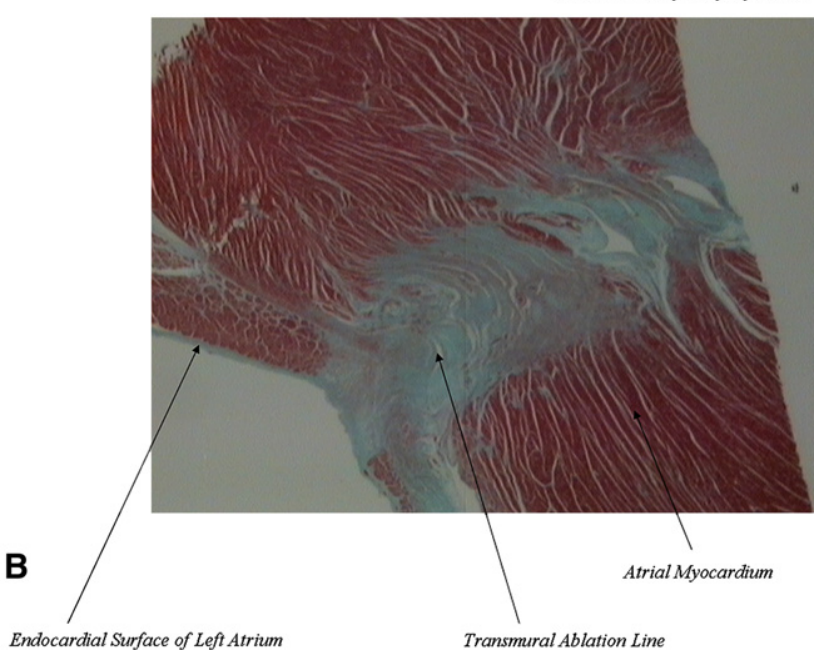

FIGURE 3. Gross and microscopic histology. A, Discrete linear ablation line across the left atrium to the mitral valve. B, Trichrome-stained microscopic histology reveals discrete, transmural lesions across the left atrial myocardium.

seconds; $P=.052$ ), the mean energy delivered during the ablations was less $(89.1 \pm 59.4 \mathrm{~J}$ versus $109.4 \pm 33.5 \mathrm{~J} ; P$ $=.016)$, and the mean maximal temperature was lower $\left(46.5^{\circ} \mathrm{C} \pm 4.6^{\circ} \mathrm{C}\right.$ vs $\left.51.9^{\circ} \mathrm{C} \pm 3.2^{\circ} \mathrm{C} ; P<.001\right) .{ }^{15}$

Histologic examination of the ablated tricuspid and mitral valve tissue revealed a discrete ablation line without perforation of the leaflets. The subvalvular apparatus remained intact. There was no identifiable valvular thrombus.

\section{Cardiac MRI Data}

Preoperative and 30-day postoperative MRI data were compared among the 6 animals that underwent the Cox maze IV procedure. No postoperative PV stenosis was identified in any animal. Quantitative flow study revealed no significant evidence of tricuspid or mitral regurgitation in either the preoperative or postoperative MRI, with a regurgitant fraction of less than $5 \%$ in every animal. Postoperative MRI did not detect any coronary artery stenosis or thrombosis in the ablated areas. The right coronary and circumflex coronary arteries were patent in every animal 30 days after the procedure.

There was no significant difference in the MRI-derived preoperative versus postoperative left ventricular EF $(50 \%$ $\pm 12 \%$ vs $41 \% \pm 9 \% ; P=.550)$. Left atrial contractility was preserved postoperatively in all animals, as confirmed by the presence of the $a$ wave, the peak velocity of atrial filling. However, there was a significant decrease in left atrial EF postoperatively $(23 \% \pm 10 \%$ vs $8 \% \pm 3 \% ; P=.021)$.

\section{DISCUSSION}

Owing to the advances in surgical ablation technology, the original "cut-and-sew" Cox maze III is of historical interest only in most centers. Over the past decade, groups around the world have replaced the original incisions of the Cox maze III with ablation lines using various energy sources. These energy sources include cryoablation, RF energy, microwave, laser, and high-frequency focused ultrasound. ${ }^{27}$ With the exception of RF energy, all other energy sources have used unipolar sources to create the ablation lines.

The unipolar energy sources have limitations. These devices are not capable of indicating when the ablation results in a transmural lesion. Moreover, many of these devices were released clinically without accurate doseresponse curves, which has resulted in occasional collateral cardiac and extracardiac damage. ${ }^{28-30}$ Furthermore, studies have shown that unipolar technologies have difficulty creating transmural lesions when applied epicardially on a beating heart, limiting their efficacy for less-invasive applications such as off cardiopulmonary bypass. ${ }^{31-34}$

Bipolar RF ablation technology has been able to overcome some of the shortcomings associated with the unipolar devices. ${ }^{13-16,35}$ Bipolar RF devices deliver focused energy between 2 closely approximated electrodes embedded into the jaws of the clamp, creating discrete linear lesions. The focused energy reduces the possibility of collateral damage. Moreover, these devices are capable of measuring the conductance between the 2 electrodes, and algorithms have been developed that have accurately predicted lesion transmurality. ${ }^{13-16}$ The biggest limitation of bipolar devices is that they can only ablate atrial tissue that can physically be clamped within the jaws of the device. This has limited the lesion sets that can be clinically created, particularly on the beating heart. For example, bipolar devices have not been able to create the left and right atrial isthmus lesions of the Cox maze IV procedure. ${ }^{17}$

There have been recent efforts to further improve the bipolar RF ablation devices. Initial clinical experience from our center showed that a single ablation did not reliably create conduction block as determined by pacing. ${ }^{18}$ The Isolator II device was developed in an attempt to create wider ablation lines and to reliably penetrate thicker tissue. The results of this study confirm that the Isolator II device 
did create slightly wider lesions than its predecessor (the Isolator device) and was able to create long-term transmural lesions in the beating heart $100 \%$ of the time. ${ }^{13-15}$

The new device was shown not to have any adverse effect on mitral or tricuspid valve function as measured by MRI scans. There was no evidence of subacute coronary injury, PV stenosis, or left atrial thrombus. Furthermore, left ventricular function-as determined by preoperative and postoperative left ventricular EF- was not affected by the Cox maze IV procedure performed with the Isolator II device. The left atrial EF, however, was significantly decreased 30 days after the operation. This has been shown previously with this lesion set. ${ }^{15}$

Additional testing of the efficacy of this device showed that the Cox maze IV lesion set performed with the Isolator II device was able to prevent the postoperative induction of $\mathrm{AF}$ at 30 days by burst pacing. This was in distinct comparison with the sham group, in which all animals could be induced into $\mathrm{AF}$ at late follow-up.

There are several limitations to this study. The results of an experimental study must be cautiously applied to the clinical situation. First, there are anatomic differences in the porcine and the human heart. Humans have larger PVs with more surrounding fat. In addition, this study was performed on normal porcine atria and not on the diseased and often thickened human atria seen in patients with long-standing AF. Our early and midterm clinical experience using cardiopulmonary bypass, however, has similarly documented the efficacy of creating transmural lesions with this technology. ${ }^{18,19}$ The Cox maze IV procedure used in this study involved creating ablations across the right and circumflex coronary arteries. Although there was no histologic evidence of thrombosis or stenosis, the follow-up was only 30 days and does not rule out the possibility of late injury. Therefore, it is emphasized that ablations should not be performed over coronary arteries. Finally, a significant limitation for the clinical use of this beating heart Cox maze IV procedure is the need to place the clamp inside the atrium. Although this can be performed without difficulty on the right atrium, there would be a significant risk of both bleeding and air embolus on the left side and it is not recommended for clinical use. The use of cardiopulmonary bypass or adjunctive technology development would be necessary to make this lesion set feasible on the beating heart.

In conclusion, the Isolator II device was able to reliably create transmural ablation with a single delivery of energy in every instance. The performance of the Cox maze IV lesion set with this device eliminated the ability to induce AF. Ablation of valvular tissue produced no discernible damage in valvular or ventricular function at 30 days.

We thank Diane Toeniskotter, Naomi Still, and Nai-Lun Chang for their technical assistance.

\section{References}

1. Cox JL, Schuessler RB, D'Agostino HJ Jr, Stone CM, Chang BC, Cain ME, et al. The surgical treatment of atrial fibrillation. III. Development of a definitive surgical procedure. J Thorac Cardiovasc Surg. 1991;101:569-83.

2. Cox JL. The surgical treatment of atrial fibrillation. IV. Surgical technique. J Thorac Cardiovasc Surg. 1991;101:584-92.

3. Cox JL, Canavan TE, Schuessler RB, Cain ME, Lindsay BD, Stone C, et al. The surgical treatment of atrial fibrillation. II. Intraoperative electrophysiologic mapping and description of the electrophysiologic basis of atrial flutter and atrial fibrillation. J Thorac Cardiovasc Surg. 1991;101:406-26.

4. Cox JL, Schuessler RB, Lappas DG, Boineau JP. An 8 1/2-year clinical experience with surgery for atrial fibrillation. Ann Surg. 1996;224:267-73; discussion 273-275.

5. Prasad SM, Maniar HS, Camillo CJ, Schuessler RB, Boineau JP, Sundt TM 3rd, et al. The Cox maze III procedure for atrial fibrillation: long-term efficacy in patients undergoing lone versus concomitant procedures. J Thorac Cardiovasc Surg. 2003;126:1822-8.

6. McCarthy PM, Gillinov AM, Castle L, Chung M, Cosgrove D 3rd. The Cox-Maze procedure: the Cleveland Clinic experience. Semin Thorac Cardiovasc Surg. 2000;12:25-9.

7. Raanani E, Albage A, David TE, Yau TM, Armstrong S. The efficacy of the Cox/ maze procedure combined with mitral valve surgery: a matched control study. Eur J Cardiothorac Surg. 2001;19:438-42.

8. Schaff HV, Dearani JA, Daly RC, Orszulak TA, Danielson GK. Cox-Maze procedure for atrial fibrillation: Mayo Clinic experience. Semin Thorac Cardiovasc Surg. 2000;12:30-7.

9. Cox JL, Boineau JP, Schuessler RB, Jaquiss RD, Lappas DG. Modification of the maze procedure for atrial flutter and atrial fibrillation. I. Rationale and surgical results. J Thorac Cardiovasc Surg. 1995;110:473-84.

10. Viola N, Williams MR, Oz MC, Ad N. The technology in use for the surgical ablation of atrial fibrillation. Semin Thorac Cardiovasc Surg. 2002;14:198-205.

11. Williams MR, Garrido M, Oz MC, Argenziano M. Alternative energy sources for surgical atrial ablation. J Card Surg. 2004;19:201-6.

12. Cummings JE, Pacifico A, Drago JL, Kilicaslan F, Natale A. Alternative energy sources for the ablation of arrhythmias. Pacing Clin Electrophysiol. 2005;28: 434-43.

13. Prasad SM, Maniar HS, Schuessler RB, Damiano RJ Jr. Chronic transmural atrial ablation by using bipolar radiofrequency energy on the beating heart. $J$ Thorac Cardiovasc Surg. 2002;124:708-13.

14. Prasad SM, Maniar HS, Diodato MD, Schuessler RB, Damiano RJ Jr. Physiolog ical consequences of bipolar radiofrequency energy on the atria and pulmonary veins: a chronic animal study. Ann Thorac Surg. 2003;76:836-41; discussion $841-842$.

15. Gaynor SL, Ishii Y, Diodato MD, Prasad SM, Barnett KM, Damiano NR, et al Successful performance of Cox-Maze procedure on beating heart using bipolar radiofrequency ablation: a feasibility study in animals. Ann Thorac Surg. 2004;78: 1671-7.

16. Melby SJ, Gaynor SL, Lubahn JG, Lee AM, Rahgozar P, Caruthers SD, et al. Efficacy and safety of right and left atrial ablations on the beating heart with irrigated bipolar radiofrequency energy: a long-term animal study. I Thorac Cardiovasc Surg. 2006;132:853-60.

17. Damiano RJ Jr, Gaynor SL. Atrial fibrillation ablation during mitral valve surgery using the Atricure device. Oper Tech Thorac Cardiovasc Surg. 2004;9: 24-33.

18. Gaynor SL, Diodato MD, Prasad SM, Ishii Y, Schuessler RB, Bailey MS, et al A prospective, single-center clinical trial of a modified Cox maze procedure with bipolar radiofrequency ablation. J Thorac Cardiovasc Surg. 2004;128: 535-42.

19. Mokadam NA, McCarthy PM, Gillinov AM, Ryan WH, Moon MR, Mack MJ, et al. A prospective multicenter trial of bipolar radiofrequency ablation for atrial fibrillation: early results. Ann Thorac Surg. 2004;78:1665-70.

20. Gaynor SL, Schuessler RB, Bailey MS, Ishii Y, Boineau JP, Gleva MJ, et al. Surgical treatment of atrial fibrillation: predictors of late recurrence. $J$ Thorac Cardiovasc Surg. 2005;129:104-11.

21. Melby SJ, Kaiser SP, Bailey MS, Zierer A, Voeller RK, Lall SC, et al. Surgical treatment of atrial fibrillation with bipolar radiofrequency ablation: mid-term results in one hundred consecutive patients. J Cardiovasc Surg (Torino). 2006; 47:705-10.

22. Melby SJ, Zierer A, Bailey MS, Cox JL, Lawton JS, Munfakh N, et al. A new era in the surgical treatment of atrial fibrillation: the impact of ablation technology and lesion set on procedural efficacy. Ann Surg. 2006;244:583-92. 
23. Lall SC, Melby SJ, Voeller RK, Zierer A, Bailey MS, Guthrie TJ, et al. The effect of ablation technology on surgical outcomes after the Cox-maze procedure: a propensity analysis. J Thorac Cardiovasc Surg. 2007;133:389-96.

24. Naylor GL, Firimin DN, Longmore DB. Blood flow imaging by cine magnetic resonance. J Comput Assist Tomogr. 1986;10:715-22.

25. Botnar RM, Stuber M, Danias PG, Kissinger KV, Manning WJ. Improved coronary artery definition with T2-weighted, free-breathing, three-dimensional coronary MRA. Circulation. 1999;99:3139-48.

26. Prasad SM, Maniar HS, Moustakidis P, Schuessler RB, Damiano RJ Jr. Epicardial ablation on the beating heart: progress towards an off-pump maze procedure. Heart Surg Forum. 2002;5:100-4.

27. Melby SJ, Lee AM, Damiano RJ Jr. Advances in surgical ablation devices for atrial fibrillation. New arrhythmia technologies. Malden (MA): Blackwell Publishing; 2005. p. 233-41.

28. Gillinov AM, Pettersson G, Rice TW. Esophageal injury during radiofrequency ablation for atrial fibrillation. J Thorac Cardiovasc Surg. 2001;122:1239-40.

29. Laczkovics A, Khargi K, Deneke T. Esophageal perforation during left atrial radiofrequency ablation. J Thorac Cardiovasc Surg. 2003;126:2119-20. author reply 2120.
30. Demaria RG, Page P, Leung TK, Dubuc M, Malo O, Carrier M, et al. Surgical radiofrequency ablation induces coronary endothelial dysfunction in porcine coronary arteries. Eur J Cardiothorac Surg. 2003;23:277-82.

31. Doll N, Kornherr P, Aupperle H, Fabricius AM, Kiaii B, Ullmann C, et al. Epicardial treatment of atrial fibrillation using cryoablation in an acute off-pump sheep model. Thorac Cardiovasc Surg. 2003;51:267-73.

32. Thomas SP, Guy DJ, Boyd AC, Eipper VE, Ross DL, Chard RB. Comparison of epicardial and endocardial linear ablation using handheld probes. Ann Thorac Surg. 2003;75:543-8.

33. Santiago T, Melo J, Gouveia RH, Neves J, Abecasis M, Adragão P, et al. Epicardial radiofrequency applications: in vitro and in vivo studies on human atrial myocardium. Eur J Cardiothorac Surg. 2003;24:481-6; discussion 486.

34. van Brakel TJ, Bolotin G, Salleng KJ, Nifong LW, Allessie MA, Chitwood WR Jr, et al. Evaluation of epicardial microwave ablation lesions: histology versus electrophysiology. Ann Thorac Surg. 2004;78:1397-402; discussion 1397-1402.

35. Khargi K, Deneke T, Haardt H, Lemke B, Grewe P, Müller KM, et al. Saline-irrigated, cooled-tip radiofrequency ablation is an effective technique to perform the maze procedure. Ann Thorac Surg. 2001;72:S1090-5. 